\title{
Histological and Clinical Characteristics of Patients with Chronic Hepatitis C and Persistently Normal Alanine Aminotransferase Levels
}

\author{
Bakht Roshan ${ }^{1}$ and Grace Guzman ${ }^{2}$ \\ ${ }^{1}$ Department of Medicine, Section of Hepatology, University of Illinois at Chicago, 840 South Wood Street, Suite 130, \\ Chicago, IL 60612, USA \\ ${ }^{2}$ Department of Pathology (MC847), University of Illinois at Chicago, 840 South Wood Street, Suite 130, Chicago, IL 60612, USA
}

Correspondence should be addressed to Bakht Roshan; bakhtroshan@gmail.com

Received 4 March 2014; Revised 23 April 2014; Accepted 23 April 2014; Published 7 May 2014

Academic Editor: Annarosa Floreani

Copyright (C) 2014 B. Roshan and G. Guzman. This is an open access article distributed under the Creative Commons Attribution License, which permits unrestricted use, distribution, and reproduction in any medium, provided the original work is properly cited.

\begin{abstract}
Patients with chronic hepatitis C virus (HCV) infection and persistently normal alanine aminotransferase (PNALT) are generally described to have mild liver disease. The aim of this study was to compare clinical and histological features in HCV-infected patients with PNALT and elevated ALT. Patients presenting to the University of Illinois Medical Center, Chicago, who had biopsy proven $\mathrm{HCV}$, an ALT measurement at the time of liver biopsy, at least one additional ALT measurement over the next 12 months, and liver biopsy slides available for review were identified. PNALT was defined as ALT $\leq 30$ on at least 2 different occasions over 12 months. Of 1200 patients with HCV, 243 met the study criteria. 13\% (32/243) of patients had PNALT while 87\% (211/243) had elevated ALT. Significantly more patients with PNALT had advanced fibrosis (F3 and F4) compared to those with elevated ALT $(P=0.007)$. There was no significant difference in the histology activity index score as well as mean inflammatory score between the two groups. In conclusion, in a well-characterized cohort of patients at a tertiary medical center, PNALT did not distinguish patients with mild liver disease.
\end{abstract}

\section{Introduction}

Hepatitis C virus (HCV) infection is reported to have a prevalence of approximately $3 \%$ worldwide [1]. Almost $80 \%$ of those infected go on to develop chronic infection. Majority of patients with chronic HCV have a mild, asymptomatic elevation in serum transaminase levels with no significant clinical symptoms. Around $25 \%$ of patients with chronic HCV have persistently normal alanine aminotransferase (PNALT) [2].

Definition of normal alanine aminotransferase (ALT) has changed over time and reference range for normal ALT differs based on different laboratory cutoffs. Prati et al. [3] in 2002 suggested new cutoffs with $30 \mathrm{U} / \mathrm{L}$ (international unit) for men and $19 \mathrm{U} / \mathrm{L}$ for women compared to $40 \mathrm{U} / \mathrm{L}$ and $30 \mathrm{U} / \mathrm{L}$ for men and women, respectively. This resulted in improved sensitivity but decreased specificity. Similarly, definition of
PNALT differs widely. A 2009 American Association for the Study of Liver Disease (AASLD) practice guideline suggested an ALT value of $40 \mathrm{U} / \mathrm{L}$ on 2-3 different occasions separated by at least a month over a period of 6 months [4]. Others have used 3 different ALT levels equal to or below upper limit of normal (ULN) separated by at least 1 month and sometimes over a period of 18 months [5]. Thus, there is no consensus on a universal definition of PNALT.

It was generally thought that people with PNALT have a mild liver disease and the degree of liver fibrosis is minimal [6-14]. Based on this, people with PNALT were initially monitored conservatively without treatment. Later on, it was realized that a considerable number of such patients developed significant inflammation and fibrosis over time [15]. More recently, treatment has been recommended along the same lines for patients with PNALT as patients with elevated ALT [4]. 
TABLE 1: ALT range expressed in international unit (U/L).

\begin{tabular}{lcccc}
\hline Interval & Biopsy & 3 months & 6 months & 12 months \\
\hline PNALT (median) & $9-30(24)$ & $9-28(20)$ & $10-30(22)$ & $11-30(21)$ \\
Elevated ALT (median) & $16-987(56)$ & $14-57(27)$ & $12-1248(45)$ & $10-231(43)$ \\
\hline
\end{tabular}

Although more data is becoming available about the relationship of liver enzymes and course of chronic $\mathrm{HCV}$ infection, data regarding $\mathrm{HCV}$ infection and PNALT is relatively scarce. Because of variation in the definition of PNALT, fewer studies have looked at the relationship of PNALT with chronic HCV infection using updated normal ALT definitions [16].

Department of Hepatology at the University of Illinois (U of I) medical center, Chicago, had a database of over 1200 patients with chronic HCV infection. Medical records of these patients were reviewed in an effort to characterize patients with chronic HCV infection and PNALT. Histological and clinical parameters for patients with PNALT as well as elevated ALT were analyzed.

\section{Materials and Methods}

Database of patients with $\mathrm{HCV}$ infection presenting to U of I medical center, Chicago, was reviewed. These patients had a liver biopsy done between 1996 and 2007. Patients with biopsy proven $\mathrm{HCV}$ infection and a detectable $\mathrm{HCV}$ ribonucleic acid (RNA) in blood were chosen. Of these, patients with an ALT at liver biopsy, at least one additional over the next 12 months, and liver biopsy slides available for review were identified.

Most of the liver biopsy procedures were done at $U$ of I medical center and in cases where biopsies were done at outside facility they were read again at $U$ of I medical center. Two expert hepatologists, who were masked to clinical data, assigned Knodell et al. [17] score to liver biopsies. Intervals for ALT measurement were chosen around the time of liver biopsy as well as 3, 6, and 12 months after biopsy. Patients with end-stage renal disease like those on dialysis and stage IV chronic kidney disease with creatinine clearance of 15-29, those who received organ transplant, those with co-infection with HIV, those who were positive for Hepatitis B surface antigen (HBsAg), and those receiving antiviral therapy for chronic HCV were excluded.

PNALT was defined as ALT $\leq 30 \mathrm{U} / \mathrm{L}$ on at least 2 different occasions over 12 months. Strict PNALT was defined as ALT $\leq$ $30 \mathrm{U} / \mathrm{L}$ for males and $\leq 19 \mathrm{U} / \mathrm{L}$ for females.

Demographic data including age at biopsy, gender, and race were recorded. Clinical data included body mass index (BMI), alcohol use, tobacco use, and presence of diabetes mellitus (DM). HCV virus was further characterized by recording HCV RNA levels, genotype, and duration of infection. Histological data included individual markers of inflammation like portal tract inflammation, piece meal necrosis, and lobular inflammation as well as fibrosis according to Knodell et al. scoring system. Inflammatory score (sum of portal tract inflammation, piece meal necrosis, and lobular inflammation) and histologic activity index (HAI) score (sum of inflammatory score and fibrosis) were calculated. Histologic data from PNALT was then compared with patients from elevated ALT group. Finally, clinical characteristics of PNALT with advanced fibrosis were compared with PNALT but with no advanced fibrosis.

Statistical analysis was performed using SPSS (SPSS Inc., Chicago, IL). Independent sample $t$-test and chi-squared test were used to calculate $P$ values where appropriate.

\section{Results}

A total of 243 patients out of a database of 1200 patients with HCV satisfied the study criteria. Main reasons to exclude a large number of patients were a lack of detectable RNA despite biopsy report, outside biopsy report but slides not available for review, single or no ALT value, and patients undergoing treatments. Those analyzed were further divided into PNALT, strict PNALT, and elevated ALT group. 32 (13\%) of these patients were identified as PNALT group and 211 (87\%) were identified as elevated ALT group. Only 13 (5\%) patients satisfied criterion for strict PNALT and this group was not analyzed further. The range of ALT values at different time intervals was specified (Table 1). 24 (75\%) of PNALT patients were females while 85 (40\%) with elevated ALT were females. 13 (41\%) with PNALT were African American (AA) compared to $87(41 \%)$ with elevated ALT, 14 (44\%) were Caucasian (W) compared to 79 (38\%) with elevated ALT, and $5(15 \%)$ were Hispanic $(\mathrm{H})$ compared to $44(21 \%)$ with elevated ALT. There was no statistically significant difference in the racial distribution between PNALT and elevated ALT group.

There was a higher frequency of women in the PNALT group compared to the elevated ALT group $(P=0.001)$. Diabetes and alcohol use were more common among patients with elevated ALT compared to PNALT $(P=0.04$ and 0.049 , resp.). Most notably, patients with PNALT had a higher rate of cirrhosis $(P=0.007)$. There were no differences in age at biopsy, tobacco use, BMI, RNA level, and duration of infection between PNALT and elevated ALT groups (Table 2).

Further evaluation of liver histology showed no statistically significant difference in mean fibrosis score, mean portal tract inflammation score, mean piecemeal necrosis score (PMN), mean lobular inflammation score, mean histologic activity index (HAI) score, and mean inflammatory score between PNALT group and elevated ALT group (Table 3). Comparison of clinical characteristics of PNALT group with advanced fibrosis with PNALT group without advanced fibrosis showed that only platelet count was significantly different between the two groups (Table 4). Tables 5 and 6 characterize the distribution of HCV genotypes based on PNALT and HAI score, respectively. 
TABLE 2: Clinical data/distribution of patients.

\begin{tabular}{|c|c|c|c|c|}
\hline & $\begin{array}{l}\text { PNALT } \\
(n=32)\end{array}$ & $\begin{array}{l}\text { Elevated ALT } \\
\quad(n=211)\end{array}$ & $\begin{array}{c}\text { Total } \\
(n=243)\end{array}$ & $P$ value \\
\hline Gender M/F & $8 / 24$ & $126 / 85$ & $134 / 109$ & 0.001 \\
\hline Race (W/AA/H) & $14 / 13 / 5$ & $79 / 87 / 44$ & $93 / 100 / 49^{*}$ & 0.717 \\
\hline Alcohol (Y/N) & $6 / 26$ & $77 / 134$ & $83 / 160$ & 0.049 \\
\hline $\operatorname{Tobacco}(\mathrm{Y} / \mathrm{N})$ & $6 / 26$ & $30 / 181$ & $36 / 207$ & 0.501 \\
\hline $\mathrm{DM}(\mathrm{Y} / \mathrm{N})$ & $2 / 30$ & $46 / 165$ & $48 / 195$ & 0.04 \\
\hline Mean age at biopsy in years $(n)$ & $50(31)$ & $47(211)$ & $242^{*}$ & 0.153 \\
\hline Mean BMI $(n)$ & $26(27)$ & $25(177)$ & $204^{*}$ & 0.5 \\
\hline Mean RNA level in IU/mL $(n)$ & $1883693(30)$ & $4439614(159)$ & $189^{*}$ & 0.09 \\
\hline Duration of infection in years $(n)$ & $26(21)$ & $25(152)$ & $173^{*}$ & 0.768 \\
\hline Fibrosis (F0-1/F2-4) & $10 / 22$ & $84 / 127$ & $94 / 149$ & 0.354 \\
\hline Fibrosis (F0-2/F3-4) & $24 / 8$ & $192 / 19$ & $216 / 27$ & 0.007 \\
\hline
\end{tabular}

${ }^{*}$ Data not available for all patients.

TABLE 3: Histological data.

\begin{tabular}{lccc}
\hline & $\begin{array}{c}\text { PNALT } \\
(\text { mean } \pm \text { SD })\end{array}$ & $\begin{array}{c}\text { Elevated ALT } \\
\text { (mean } \pm \text { SD) }\end{array}$ & $P$ value \\
\hline Fibrosis & $2 \pm 1$ & $1.7 \pm 1$ & 0.067 \\
Portal tract inflammation & $1.66 \pm 1$ & $1.77 \pm 1$ & 0.46 \\
PMN & $1.47 \pm 1$ & $1.48 \pm 1$ & 0.96 \\
Lobular inflammation & $0.72 \pm 1$ & $0.9 \pm 1$ & 0.175 \\
HAI score & $6 \pm 3$ & $6 \pm 3$ & 0.94 \\
Inflammatory score & $4 \pm 2$ & $4 \pm 2$ & 0.7 \\
\hline
\end{tabular}

TABLE 4: PNALT with advanced fibrosis versus PNALT without advanced fibrosis.

\begin{tabular}{|c|c|c|c|c|}
\hline & $\begin{array}{c}\text { PNALT with } \\
\text { advanced fibrosis }\end{array}$ & $\begin{array}{l}\text { PNALT without } \\
\text { advanced fibrosis }\end{array}$ & $\begin{array}{l}\text { Total number } \\
\text { of patients } \\
n=32\end{array}$ & $P$ value \\
\hline Mean age at biopsy in years $(n)$ & $48(8)$ & $50(23)$ & $31^{*}$ & 0.7 \\
\hline ALT at biopsy in U/L $(n)$ & $23(7)$ & $21(24)$ & $31^{*}$ & 0.5 \\
\hline ALT at 12 months in U/L $(n)$ & $21(4)$ & $21(19)$ & $23^{*}$ & 0.88 \\
\hline Mean RNA level in IU ( $n)$ & $134288(6)$ & $2321044(24)$ & $30^{*}$ & 0.127 \\
\hline Mean BMI $(n)$ & $27(6)$ & $26(21)$ & $27^{*}$ & 0.634 \\
\hline $\operatorname{AST}(n)$ & $41(7)$ & $28(24)$ & $31^{*}$ & 0.061 \\
\hline Platelet count $(n)$ & $81000(5)$ & $257000(21)$ & $26^{*}$ & 0.001 \\
\hline
\end{tabular}

${ }^{*}$ Data not available for all patients.

TABLE 5: HCV genotype characteristics.

\begin{tabular}{|c|c|c|c|c|}
\hline Genotype & $\operatorname{PNALT}(n)$ & Elevated ALT $(n)$ & Total (\%) & $P$ value \\
\hline 1 & 3 & 16 & $19(11)$ & \multirow{8}{*}{0.8} \\
\hline la & 10 & 60 & $70(39)$ & \\
\hline $1 \mathrm{~b}$ & 8 & 49 & $57(31)$ & \\
\hline $2 \mathrm{a}$ & 1 & 5 & $6(3)$ & \\
\hline $2 b$ & 0 & 13 & $13(7)$ & \\
\hline $3 a$ & 1 & 13 & $14(8)$ & \\
\hline 4 & 0 & 2 & $2(1)$ & \\
\hline Total & 23 & 158 & $181(100)$ & \\
\hline
\end{tabular}


TABLE 6: HCV genotype and HAI score.

\begin{tabular}{|c|c|c|c|c|c|}
\hline \multirow{2}{*}{ Genotype } & \multicolumn{3}{|c|}{ HAI score } & \multirow[b]{2}{*}{ Total (\%) } & \multirow{2}{*}{$P$ value } \\
\hline & $\leq 6$ & $7-12$ & $>13$ & & \\
\hline 1 & 16 & 3 & 0 & 19 (11) & \\
\hline la & 45 & 25 & 0 & $70(39)$ & \\
\hline $1 \mathrm{~b}$ & 38 & 16 & 3 & $57(31)$ & \\
\hline $2 \mathrm{a}$ & 4 & 2 & 0 & $6(3)$ & 0.34 \\
\hline $2 b$ & 6 & 7 & 0 & $13(7)$ & \\
\hline $3 a$ & 9 & 5 & 0 & $14(8)$ & \\
\hline 4 & 2 & 0 & 0 & $2(1)$ & \\
\hline Total (\%) & $120(66)$ & $58(32)$ & $3(2)$ & $181(100)$ & \\
\hline
\end{tabular}

TABle 7: ALT value and HAI score within PNALT.

\begin{tabular}{|c|c|c|c|c|c|}
\hline & \multicolumn{3}{|c|}{ HAI score } & \multirow{2}{*}{ Total } & \multirow{2}{*}{$P$ value } \\
\hline & $\leq 6$ & $7-12$ & $>13$ & & \\
\hline \multicolumn{6}{|c|}{ ALT value } \\
\hline$<19$ & 7 & 1 & 0 & 8 & \\
\hline $20-30$ & 15 & 8 & 1 & 24 & 0.4 \\
\hline Total & 22 & 9 & 1 & 32 & \\
\hline
\end{tabular}

\section{Discussion}

The natural history of chronic HCV infection with PNALT is poorly understood [18-20]. We attempt to describe the characteristics of patients with PNALT, which constitutes almost $25-30 \%$ of patients with chronic HCV infection. There are few significant findings from this work. Firstly, a high proportion of patients with PNALT had advanced fibrosis, and degree of inflammation was not significantly different than chronic HCV infection with abnormal ALT. Secondly, it was difficult to identify a substantially large set of patients with HCV infection and PNALT given that there is a significant fluctuation in the ALT level over time $[9,15]$. Thirdly, patients with multiple comorbidities were excluded leaving a small cohort size.

We chose duration of 12 months to observe the levels of ALT instead of 6 months period. It is becoming clear that 6 months is probably too short given that in some cases ALT level may fluctuate after initial period of stability [7, 21-24]. Most patients with PNALT were females, which is consistent with earlier findings [7-9]. Abstinence from alcohol and lack of DM were associated with PNALT. There was no association with race. Similarly, age at biopsy, BMI, RNA level, and duration of infection were not significantly different between the two groups. HCV genotype distribution showed that a majority $(81 \%)$ of patients belonged to genotype 1 and it is a well-characterized fact [25]. There was no significant difference in terms of distribution of genotypes between the 2 groups (Table 5). Also there was no significant difference in HAI according to genotype distribution (Table 6). HCV genotyping was performed in 181/243 (75\%) patients and was missing in $62(25 \%)$ patients. The likely reason was transition from paper to electronic records in 1990s and loss of some data.
Within PNALT, those with advanced fibrosis differed from those without advanced fibrosis by platelet count only. Other variables as shown in Table 4 did not achieve a significance level. Similarly, PNALT patients were divided based on low-normal ALT (<19) and high-normal ALT (20-30) for comparing HAI scores among them but no significance was seen (Table 7).

The most interesting finding was the comparison of histological data. Studies to date have been mentioning a milder disease for PNALT in terms of fibrosis and necroinflammation [7-9, 26-28]. Our study indicated that fibrosis and necroinflammation were comparable in both groups. Some studies have pointed to this fact as well $[14,29,30]$. This is an interesting finding given that despite significant inflammation (comparable to abnormal ALT) the ALT levels in some of these patients have been consistently low. The exact etiology of PNALT despite significant inflammation is not clear. Similarly, advanced fibrosis was more common in PNALT group as compared to the elevated ALT group $(P=$ 0.007). It is thought that ALT levels normalize in patients with advanced fibrosis [31] and that is why some authors will advocate doing liver biopsy in patients with $\mathrm{HCV}$ infection and normal ALT levels [32]. It is interesting to note that the 6 patients with PNALT who had cirrhosis also had evidence of thrombocytopenia. Thrombocytopenia is a well-established marker of cirrhosis [33]. Our results indicate that platelet count can be used as a marker to predict fibrosis in patients with PNALT.

There were several limitations to this study. First, it was a retrospective study. Cases were excluded because only a single measurement was available. For instance, almost all patients in the study group had an ALT measured around biopsy but only slightly more than half had ALT measured around 12 months. This is why ALT was recorded around 3 months and 
6 months as well. Second, sample size was relatively small and might not be a true representative of patients with PNALT. This might in particular be valid for PNALT with advanced fibrosis as $8(25 \%)$ out of 32 patients with PNALT had F3-F4 while only $19(9 \%)$ out of 211 patients with elevated ALT had F3-F4 $(P=0.007)$. It is not clear if the outcome would have been the same if denominator for PNALT was high.

Small sample size was caused mainly as described before as well as comorbid conditions like advanced kidney disease, HIV, HBsAg positive, and being on antiviral treatment. For example, 11 patients with PNALT were excluded as they had ESRD; ALT levels are known to be lower in ESRD [34, 35] secondary to an impaired immune response in patients with ESRD [36]. Third, ALT levels were measured at irregular intervals. This raises concern that those with PNALT and severe liver fibrosis may have been in biochemical remission. For example, of the 8 patients with severe liver fibrosis (stages 3 and 4 ) and PNALT, only 2 patients had 4 ALT measurements over 12 months (over the period of $0,3,6$, and 12 months), while 3 patients had 3 ALT measurements over 12 months, and the remaining 3 patients had only 2 ALT measurements over the 12 months period. Thus, it is not possible to say with certainty that all patients with PNALT and severe liver damage had uniformly low ALT all along.

\section{Conclusion}

In conclusion, histological changes observed in $\mathrm{HCV}$ patients with PNALT will argue that ALT is not a reliable indicator of hepatic inflammation or fibrosis. In fact, PNALT was associated with advanced fibrosis in the current study. Female gender, absence of DM, and abstinence from alcohol were associated with PNALT. Platelet count could be used to predict fibrosis in patients with PNALT. These findings indicate the need for more studies with higher number of PNALT patients to look at the relationship of PNALT with changes occurring at histological and molecular levels.

\section{Conflict of Interests}

The authors declare that there is no conflict of interests regarding the publication of this paper.

\section{References}

[1] S. Pol, A. Vallet-Pichard, M. Corouge, and V. O. Mallet, "Hepatitis C: epidemiology, diagnosis, natural history and therapy," Contributions to Nephrology, vol. 176, pp. 1-9, 2012.

[2] N. Boyer and P. Marcellin, "Natural history of hepatitis C and the impact of anti-viral therapy," Forum: Trends in Experimental and Clinical Medicine, vol. 10, no. 1, pp. 4-18, 2000.

[3] D. Prati, E. Taioli, A. Zanella et al., "Updated definitions of healthy ranges for serum alanine aminotransferase levels," Annals of Internal Medicine, vol. 137, no. 1, pp. 1-10, 2002.

[4] M. G. Ghany, D. B. Strader, D. L. Thomas, and L. B. Seeff, "Diagnosis, management, and treatment of hepatitis C: an update," Hepatology, vol. 49, no. 4, pp. 1335-1374, 2009.

[5] S. Zeuzem, M. Diago, E. Gane et al., "Peginterferon alfa-2a (40 kilodaltons) and ribavirin in patients with chronic hepatitis $\mathrm{C}$ and normal aminotransferase levels," Gastroenterology, vol. 127, no. 6, pp. 1724-1732, 2004.

[6] C. Puoti, L. Bellis, A. Galossi et al., "Antiviral treatment of HCV carriers with persistently normal ALT levels," Mini-Reviews in Medicinal Chemistry, vol. 8, no. 2, pp. 150-152, 2008.

[7] M. Persico, E. Persico, R. Suozzo et al., "Natural history of hepatitis $C$ virus carriers with persistently normal aminotransferase levels," Gastroenterology, vol. 118, no. 4, pp. 760-764, 2000.

[8] M. Martinot-Peignoux, N. Boyer, D. Cazals-Hatem et al., "Prospective study on anti-hepatitis $\mathrm{C}$ virus-positive patients with persistently normal serum alanine transaminase with or without detectable serum hepatitis C virus RNA," Hepatology, vol. 34, no. 5, pp. 1000-1005, 2001.

[9] M. L. Shiffman, M. Diago, A. Tran et al., "Chronic hepatitis C in patients with persistently normal alanine transaminase levels," Clinical Gastroenterology and Hepatology, vol. 4, no. 5, pp. 645652, 2006.

[10] D. B. Strader, T. Wright, D. L. Thomas, and L. B. Seeff, "Diagnosis, management, and treatment of hepatitis C", Hepatology, vol. 39, no. 4, pp. 1147-1171, 2004.

[11] P. Mathurin, "Slow progression rate of fibrosis in hepatitis C virus patients with persistently normal alanine transaminase activity," Hepatology, vol. 27, no. 3, pp. 868-872, 1998.

[12] P. Marcellin, S. Levy, and S. Erlinger, “Therapy of hepatitis C: patients with normal aminotransferase levels," Hepatology, vol. 26, supplement 1, no. 3, pp. 133S-136S, 1997.

[13] N. C. Tassopoulos, "Treatment of patients with chronic hepatitis C and normal ALT levels," Journal of Hepatology, vol. 31, supplement 1, pp. 193-196, 1999.

[14] C. Puoti, L. Bellis, R. Guarisco, O. D. Unto, L. Spilabotti, and O. M. Costanza, "HCV carriers with normal alanine aminotransferase levels: healthy persons or severely ill patients? Dealing with an everyday clinical problem," European Journal of Internal Medicine, vol. 21, no. 2, pp. 57-61, 2010.

[15] T. Okanoue, M. Minami, A. Makiyama, Y. Sumida, K. Yasui, and Y. Itoh, "Natural course of asymptomatic hepatitis $\mathrm{C}$ virusinfected patients and hepatocellular carcinoma after interferon therapy," Clinical Gastroenterology and Hepatology, vol. 3, supplement 2, pp. S89-S91, 2005.

[16] F. M. Sanai, A. Helmy, C. Dale et al., "Updated thresholds for alanine aminotransferase do not exclude significant histological disease in chronic hepatitis C," Liver International, vol. 31, no. 7, pp. 1039-1046, 2011.

[17] R. G. Knodell, K. G. Ishak, and W. C. Black, "Formulation and application of a numerical scoring system for assessing histological activity in asymptomatic chronic active hepatitis," Hepatology, vol. 1, no. 5, pp. 431-435, 1981.

[18] L. B. Seeff, "The natural history of chronic hepatitis C virus infection," Clinics in Liver Disease, vol. 1, no. 3, pp. 587-602, 1997.

[19] L. B. Seeff, "Natural history of chronic hepatitis C," Hepatology, vol. 36, supplement 1, no. 5, pp. S35-S46, 2002.

[20] R. Zapata, "Clinical aproach to the patient with chronic hepatitis C infection and normal aminotransferases," Annals of Hepatology, vol. 9, no. 1, supplement, pp. 72-79, 2010.

[21] S. C. Gordon, J. W. Fang, A. L. Silverman, J. G. McHutchison, and J. K. Albrecht, "The significance of baseline serum alanine aminotransferase on pretreatment disease characteristics and response to antiviral therapy in chronic hepatitis C," Hepatology, vol. 32, no. 2, pp. 400-404, 2000.

[22] J. Jamal, "Clinical features of hepatitis C-infected patients with persistently normal alanine transaminase levels in 
the Southwestern United States," Hepatology, vol. 30, no. 5, pp. 1307-1311, 2000.

[23] C. Puoti, R. Castellacci, F. Montagnese et al., "Histological and virological features and follow-up of hepatitis $\mathrm{C}$ virus carriers with normal aminotransferase levels: the Italian prospective study of the asymptomatic C carriers (ISACC)," Journal of Hepatology, vol. 37, no. 1, pp. 117-123, 2002.

[24] C. Puoti, R. Guarisco, L. Bellis, and L. Spilabotti, "Diagnosis, management, and treatment of hepatitis C", Hepatology, vol. 50, no. 1, pp. 322-325, 2009.

[25] N. N. Zein, J. Rakela, E. L. Krawitt, K. R. Reddy, T. Tominaga, and D. H. Persing, "Hepatitis C virus genotypes in the United States: epidemiology, pathogenicity, and response to interferon therapy," Annals of Internal Medicine, vol. 125, no. 8, pp. 634639, 1996.

[26] C. Puoti, R. Castellacci, and F. Montagnese, "Hepatitis C virus carriers with persistently normal aminotransferase levels: healthy people or true patients?" Digestive and Liver Disease, vol. 32, no. 7, pp. 634-643, 2000.

[27] C. Puoti, A. Magrini, T. Stati et al., "Clinical, histological, and virological features of hepatitis $\mathrm{C}$ virus carriers with persistently normal or abnormal alanine transaminase levels," Hepatology, vol. 26, no. 6, pp. 1393-1398, 1997.

[28] S. Zeuzem, A. Alberti, W. Rosenberg et al., "Review article: management of patients with chronic hepatitis $C$ virus infection and "normal" alanine aminotransferase activity," Alimentary Pharmacology and Therapeutics, vol. 24, no. 8, pp. 1133-1149, 2006.

[29] J. L. Dienstag and J. G. McHutchison, "American gastroenterological association medical position statement on the management of hepatitis C," Gastroenterology, vol. 130, no. 1, pp. 225230, 2006.

[30] C. Puoti, "HCV carriers with persistently normal aminotransferase levels: normal does not always mean healthy," Journal of Hepatology, vol. 38, no. 4, pp. 529-532, 2003.

[31] D. C. Rockey, S. H. Caldwell, Z. D. Goodman, R. C. Nelson, and A. D. Smith, "Liver biopsy," Hepatology, vol. 49, no. 3, pp. 10171044, 2009.

[32] C. Puoti, R. Guarisco, L. Spilabotti et al., "Should we treat HCV carriers with normal ALT levels? the "5Ws" dilemma," Journal of Viral Hepatitis, vol. 19, no. 4, pp. 229-235, 2012.

[33] S.-N. Lu, J.-H. Wang, S.-L. Liu et al., “Thrombocytopenia as a surrogate for cirrhosis and a marker for the identification of patients at high-risk for hepatocellular carcinoma," Cancer, vol. 107, no. 9, pp. 2212-2222, 2006.

[34] H. A. Azevedo, C. A. Villela-Nogueira, R. M. Perez et al., "Similar HCV viral load levels and genotype distribution among endstage renal disease patients on hemodialysis and HCV-infected patients with normal renal function," Journal of Nephrology, vol. 20, no. 5, pp. 609-616, 2007.

[35] A. M. Contreras, I. Ruiz, G. Polanco-Cruz et al., "End-stage renal disease and hepatitis $\mathrm{C}$ infection: comparison of alanine aminotransferase levels and liver histology in patients with and without renal damage," Annals of Hepatology, vol. 6, no. 1, pp. 48-54, 2007.

[36] M. R. Hassan, N. R. N. Mustapha, F. M. Zawawi, B. S. P. Earnest, K. Voralu, and S. P. Pani, "A comparison of genotype and markers of disease severity of chronic hepatitis $\mathrm{C}$ in patients with and without end-stage renal disease," Singapore Medical Journal, vol. 52, no. 2, pp. 86-89, 2011. 


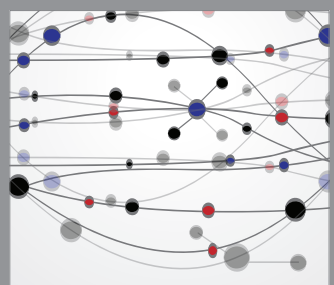

The Scientific World Journal
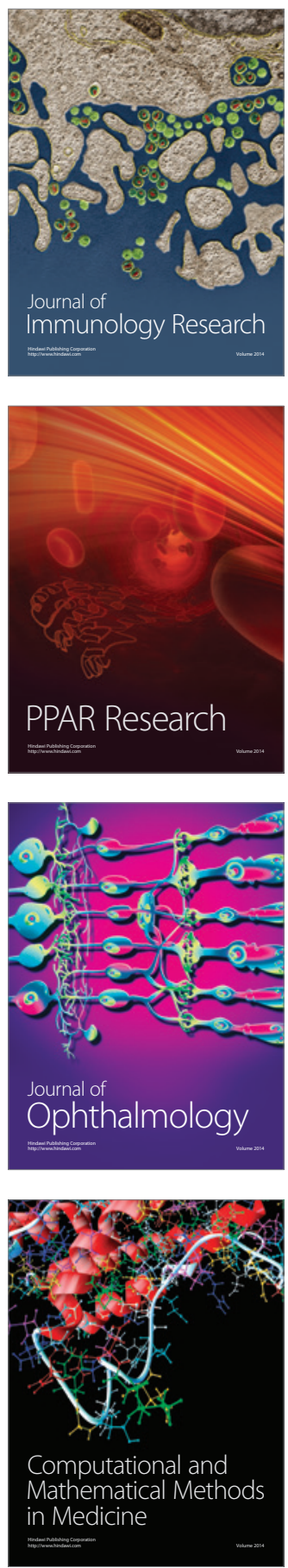

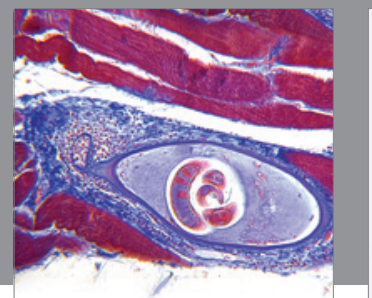

Gastroenterology

Research and Practice
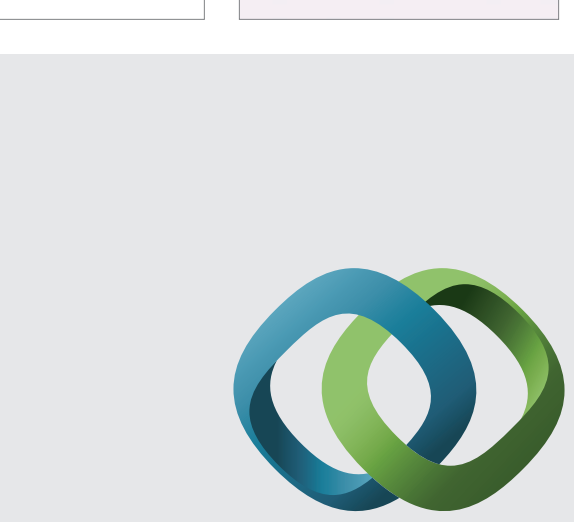

\section{Hindawi}

Submit your manuscripts at

http://www.hindawi.com
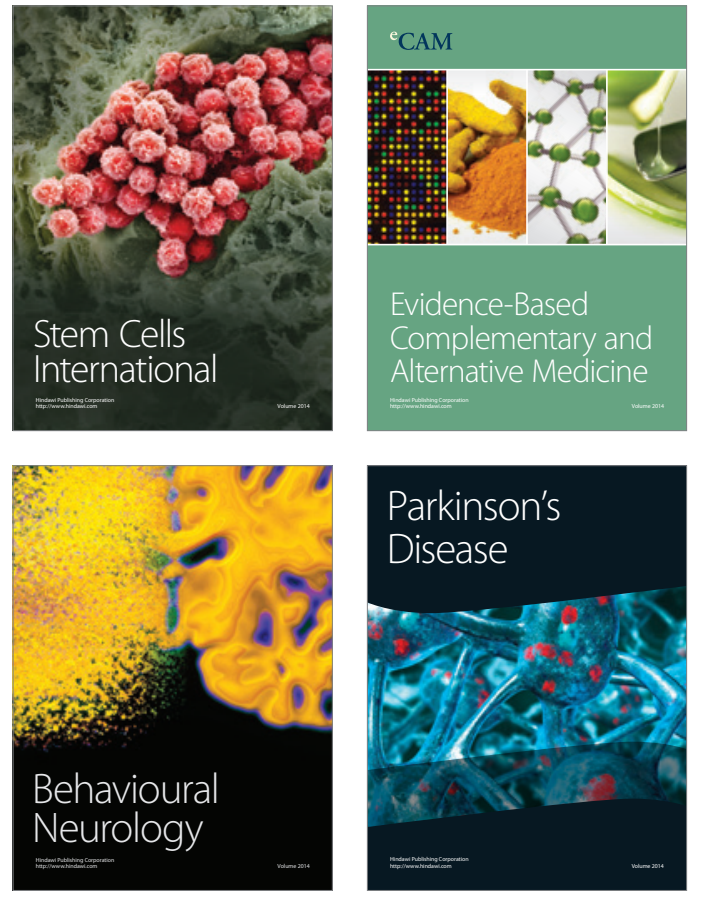
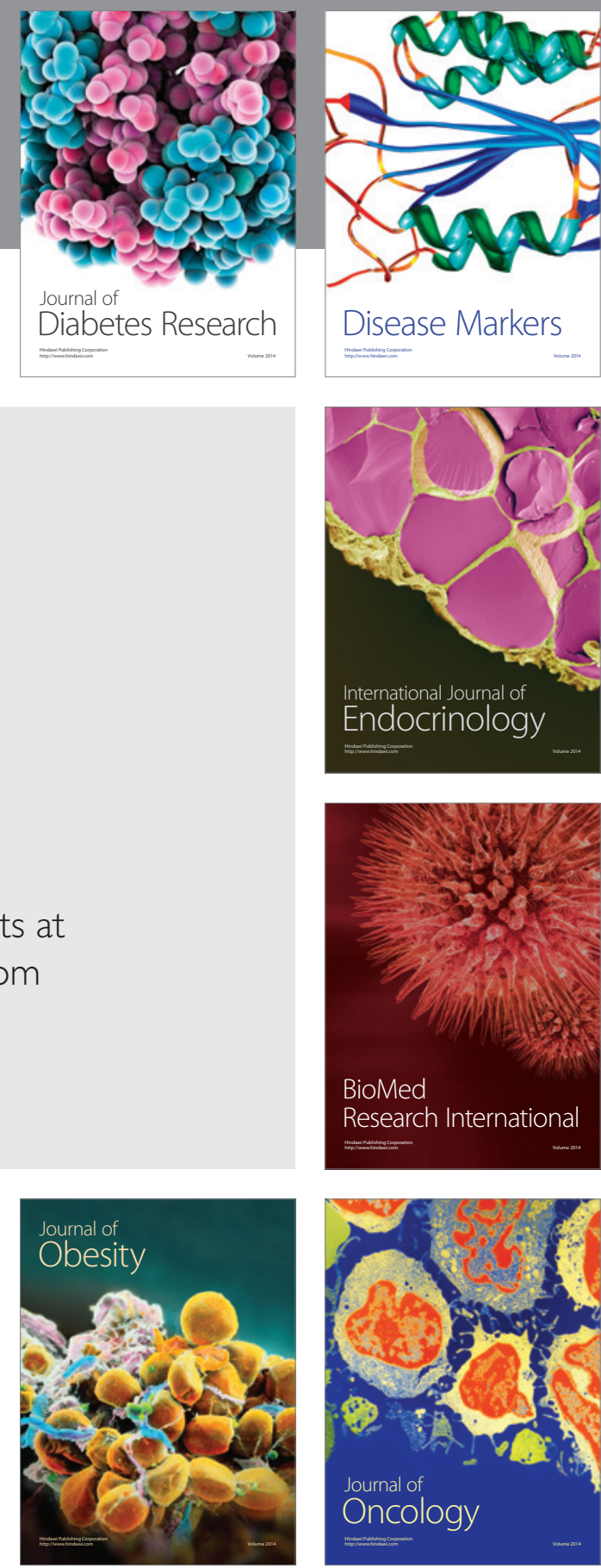

Disease Markers
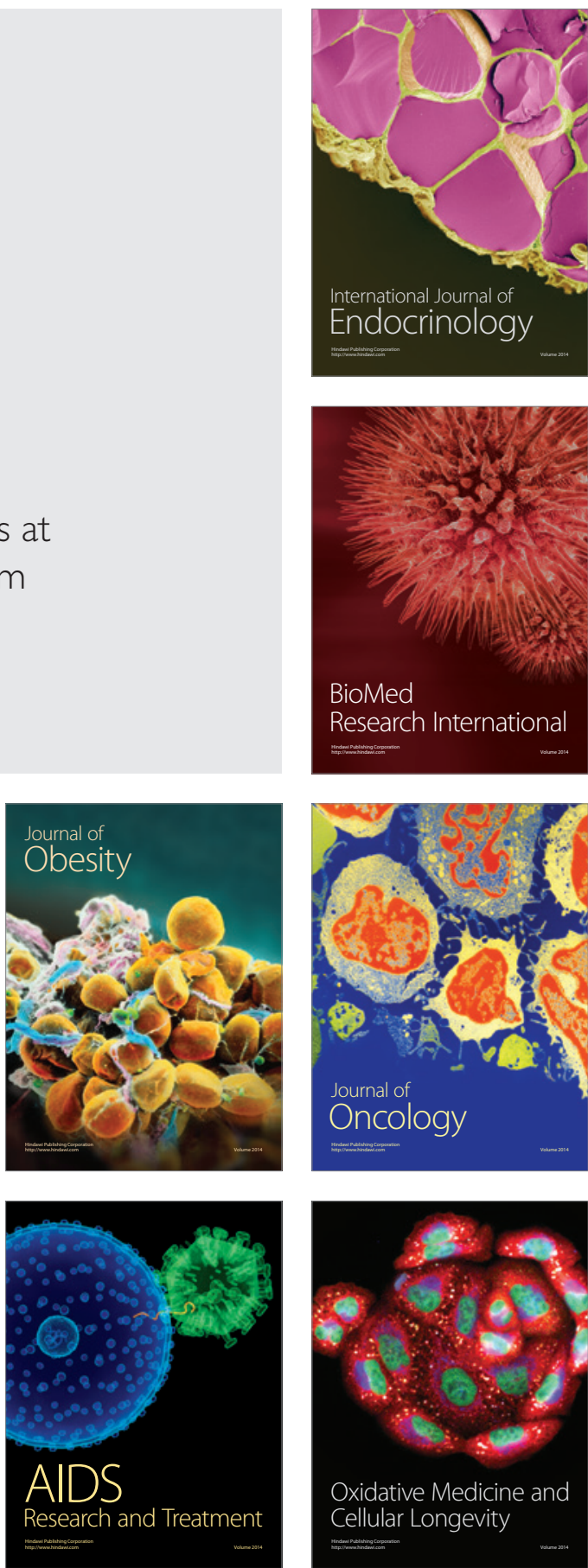